\title{
Diagnostic value of I 8F-FDG-PET and PET-CT in children with fever of unknown origin or unexplained signs of inflammation J Däbritz*1, N Jasper ${ }^{1}$, H Wittkowski ${ }^{1}, M$ Löffler $^{2}$, M Weckesser ${ }^{2}$ and D Foell ${ }^{1}$
}

\author{
Address: ${ }^{1}$ University of Muenster, Dept. of General Paediatrics, Münster, Germany and ${ }^{2}$ University of Muenster, Dept. of Nuclear Medicine, \\ Münster, Germany \\ * Corresponding author
}

\author{
from I5th Paediatric Rheumatology European Society (PreS) Congress \\ London, UK. 14-17 September 2008 \\ Published: 15 September 2008 \\ Pediatric Rheumatology 2008, 6(SuppI I):PI 27 doi:10.II86/I546-0096-6-SI-PI 27
}

This abstract is available from: http://www.ped-rheum.com/content/6/SI/PI27

(c) 2008 Däbritz et al; licensee BioMed Central Ltd.

\section{Background}

Fever of unknown origin (FUO) and unexplained signs of inflammation are challenging medical problems and predominantly caused by infections, malignancies and noninfectious inflammatory diseases. The aim of this study was to assess the diagnostic value of fluorine-18 fluorodeoxyglucose positron emission tomography (18F-FDGPET) and of its combination with computer tomography technology (PET-CT) in the diagnostic work-up in pediatric patients.

\section{Methods}

47 FDG-PET and 23 PET-CT-scans of 63 patients (median age 7,2 years, $32 \mathrm{M}, 31 \mathrm{~F}$ ) were analyzed in this retrospective study. The diagnostic value of PET investigations in pediatric patients presenting with FUO (group 1, n $=41$ scans) or unexplained signs of inflammation without fever (group 2, n = 29 scans) was analyzed.

\section{Results}

Of the total number of FDG-PET/PET-CT scans 32/57\% were clinically helpful or diagnostic, respectively. In 54\% $(\mathrm{n}=38$ ) of all scans the PET either was negative or findings could neither be confirmed nor excluded by extensive further diagnostic procedures. In scans with pathological findings $(\mathrm{n}=32)$ further investigations confirmed the PET results in $81 \%(n=26)$ of the cases. The accuracy of combined scans in these patients was $93 \%$. A diagnosis in pediatric patients with FUO could be established in 32\%, in patients with other signs of inflammation in $52 \%$.

\section{Conclusion}

This is the first study demonstrating that FDG-PET and PET-CT may be a valuable imaging technique in the evaluation of children with FUO and unexplained signs of inflammation. Pathological findings help directing the diagnostic work-up in these patients. Because of its better accuracy, PET-CT is superior to ${ }^{18}$ F-FDG-PET. 